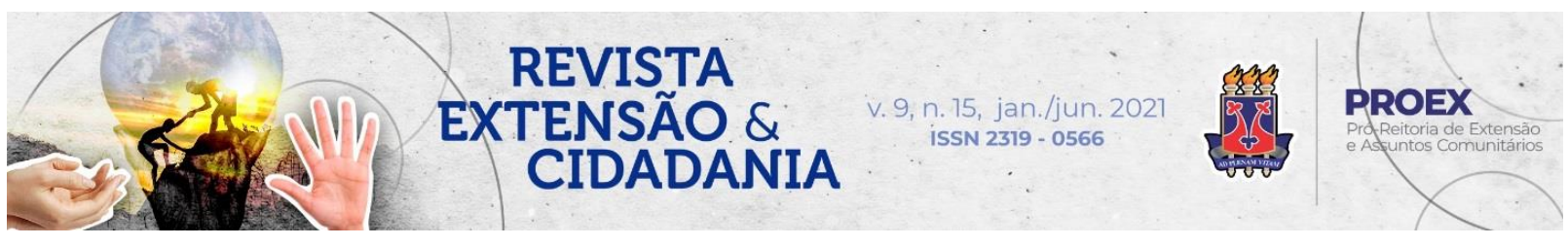

DOI: $10.22481 /$ recuesb.v9i15.8721

\title{
PROJETO DE EXTENSÃO “CINECLUBE CAFÉ COM LEITE” PARA O TRABALHO COM A DIVERSIDADE
}

\author{
“Coffee with Milk Cineclub" an extension project for working with diversity
}

\author{
Carlos Roberto Pires Campos ${ }^{1}$ \\ Gilmar Virgínio ${ }^{2}$ \\ Maria de Louldes Virgínio 3 \\ Edmar Reis Thiengo ${ }^{4}$
}

\begin{abstract}
Resumo: O cinema é uma forma criativa de estabelecer diálogos entre temas curriculares e o cotidiano da escola, além de ser uma maneira agradável de trabalhar questões polêmicas, contribuindo para a formação de criticidade. $\mathrm{O}$ artigo apresenta os resultados de um projeto de extensão escolar chamado Cineclube Café com Leite, realizado em uma escola pública estadual do Espírito Santo, buscando a promoção de debates sobre questões relativas à diversidade de gênero, ao preconceito e à intolerância. Trata-se de uma intervenção pedagógica participativa, apoiada por observações anotadas em diário de campo, colhidas em rodas de debates. Os dados foram abordados à luz dos pressupostos da teoria queer. O projeto Cineclube favoreceu aos alunos a leitura crítica do mundo e a compreensão de que as questões relacionadas à diversidade, no campo dos Direitos Humanos, são sempre acompanhadas de lutas e desafios.
\end{abstract}

Palavras-chave: Diversidade Sexual. Intolerância. Cine clube escolar. Teoria Queer.

Abstract: Cinema constitutes itself in a creative pathway to establish a dialogue between curricula and school daily life, besides being a pleasant way of exploring controvérsial issues, contributing to the formation of criticity. This article analyzes an extension school Project entitled Cine Clube Café com Leite, which was held in a public school of Espírito Santo State, seeking to promote discussion on several issues, sexual diversity, intolerance and prejudice. This is a pedagogical participatory intervention, supported by observations noted by the researcher in the debate wheel. The data were approached from the theoretical point of view.

\footnotetext{
${ }^{1}$ Arqueólogo; Doutor em História Social da Cultura, Professor do Programa de Pós-Graduação Stricto Sensu em Educação em Ciências e Matemática do IFES, Vila Velha, ES, Brasil. Orcid: 0000-0001-7708-4597 E-mail: carlosr@ifes.edu.br

${ }^{2}$ Pedagogo; Especialista em Educação Infantil. Professora da rede pública estadual do Espírito Santo, Conceição do Castelo, ES. Orcid: 0000-0001-8854-9580 E-mail: mariludavila@ hotmail.com

${ }^{3}$ Pedagoga; Especialista em Educação Infantil. Professor da rede estadual do Espírito Santo, Conceição do

Castelo, ES. Orcid: 0000-0002-3121-754X E-mail: mariludavila@hotmail.com

${ }^{4}$ Matemático; Doutor em Educação. Professor do Programa de Pós-Graduação em Educação em Ciências e Matemática, do IFES, Vitória, ES. Orcid: 0000-0002-4423-4939 E-mail: thiengo@ifes.edu.br
} 
Data indicated that the development of the Project provided an opportunity to the students to follow paths that aim to develop their critical reading of the world, and consequently to understand that issues about sexual diversity are always followed by fight sand challenges.

Keywords: Sexual Diversity. Intolerance. School cineclub. Queer theory.

\section{Introdução}

A garantia do direito à educação tem por pressuposto incluir socialmente os atores sociais, vez que a educação se configura como instância socializadora e porto seguro para o desenvolvimento da personalidade dos sujeitos. Por essa razão, o trabalho escolar funda-se em processos de aprendizagem de conteúdos e conceitos, de procedimentos e atitudes e, também, enseja a criação e a difusão de ideias de formação pública as quais embasarão a construção da cidadania.

No cotidiano das escolas, o trabalho com temas relacionados à diversidade confronta-se com práticas, muitas vezes, excludentes e preconceituosas, enraizadas em concepções tradicionais e não equânimes acerca das diversidades de gênero, orientação sexual, étnica, social e de todas as diferenças que não se conformam ao padrão de normatividade. Este mesmo padrão contribui para a ordenação de uma sociedade que se movimenta a partir de práticas sociais discriminatórias. Na trajetória dos tempos, a escola tem servido para conformar as pessoas à "normalização social, defendendo interesses biopolíticos, entre o sistema educacional e a imposição de modelos de como ser homem ou mulher, masculino e feminino, hétero ou homossexual" (MISKOLCI, 2012 p. 12).

Em face disso, desenvolvemos um projeto de extensão não fincado em conteúdos, mas, em troca de experiências decorrentes do próprio ato de aprender a conviver, uma vez que, em consonância com a visão de Butler (2003), não há um sujeito preexistente, mas sim um sujeitoem-processo que se constitui pelos atos por ele executados.

Para Pessanha (2012), a escola tem papel fundamental na mudança de rumos da sociedade, pois somente com cidadãos críticos e educados é possível construir novos valores sociais e a pluralidade de pensamentos, fortalecedores do debate político e do crescimento intelectual. As várias horas que os atores sociais passam na escola demandam que seu ambiente seja acolhedor, sem qualquer preconceito, já que a escola é um lugar de encontro social, com situações de divergências e de conflitos. Mas a não aceitação do que geralmente é rotulado

Revista Extensão \& Cidadania, v. 9, n. 15, p. 74-92, jan./jun. 2021. 
como diferente - incluindo-se nessa diferença a diversidade étnica, social, de orientação sexual e de gênero -, assim como na sociedade em geral, está presente em quase que todas as escolas, em todas as modalidades de ensino.

Ao trabalhar com os alunos do Ensino Médio, observamos que estes, em sua maioria, possuem um olhar preconceituoso acerca das diversidades. Em uma roda de conversa, percebemos que essa visão decorre não só da construção cultural, mas também da falta de informação, da visão enraizada de professores ou de fundamentalismos religiosos, pautados em uma sociedade de matizes patriarcais. A heterossexualidade em nossa sociedade está naturalmente representada, isso significa que qualquer representação fora dessa norma social e moral estará rejeitada, refutada, e sofrerá diversos tipos de preconceito.

A escola tende a movimentar-se internamente, de modo que os sujeitos que produz ajam a partir de determinados padrões. Desse ponto de vista, a escola comporta-se como um local excludente. Para Braga e Brissola (2015, p. 687), na nossa sociedade, a força "homogeneizadora da identidade considerada normal é diretamente proporcional à sua invisibilidade. As identidades hegemônicas são permanentemente incomodadas pelos 'outros', sem cuja existência elas não fariam sentido."

Sendo assim, torna-se necessária a formação de professores para o trabalho com temas relacionados à diversidade, atentos também aos pressupostos da teoria queer, para que possam ensinar e aprender com seus alunos e alunas o respeito às diferenças no ambiente educacional. Enquanto educadores, ainda continuamos reforçando modelos rígidos e estereotipados de homens e de mulheres. Discutir e problematizar as relações humanas e afetivas e suas diferenças é uma das condições indispensáveis para a superação de barreiras e de padrões supostamente normais, que têm gerado desigualdades no tratamento entre as pessoas.

Nesse cenário, a teoria queer emerge como resistência à ordem instalada, porque seu olhar insubordinado enseja uma nova forma de pensar a heteronormatividade. Se a diversidade busca a tolerância somente, a teoria queer vai além, porque para Miskolci (2012, p. 46), tolerar é diferente de reconhecer o outro, de valorizá-lo "em sua especificidade e conviver com a diversidade não quer dizer aceitá-la.” Para o autor, a simples tolerância manteria as relações intocadas.

Dessa perspectiva, faz-se urgente desenvolvermos práticas pedagógicas inovadoras no sentido de estimular, no ambiente escolar, o debate sobre as relações de gênero, de modo não hegemônico, rompendo a ideia de identidade de gênero enquanto algo estável. É preciso

Revista Extensão \& Cidadania, v. 9, n. 15, p. 74-92, jan./jun. 2021. 
reconhecer que gênero é constituído na linguagem e pela linguagem, com vistas à construção de um saber necessário para o respeito e a convivência com as diversidades.

Desenvolver a consciência crítica e a sensibilidade de alunos e professores, por meio do diálogo provocado pelo cinema, ao abordar temas que objetivam o enriquecimento das visões de mundo, pode ser um caminho para a percepção de que a única coisa de igual que temos é a nossa diferença. A teoria queer defende, pois, uma educação dialógica, na qual as experiências ofuscadas ou eclipsadas passem a compor o cotidiano escolar, aproximando a hierarquia entre quem educa e quem é educado, superando, inclusive, a relação de opressor e oprimido que, por sua natureza, é binária. Uma educação assim ensejaria um aprendizado relacional e transformador para todos da comunidade escolar (MISKOLCI, 2012). O fato é que a educação precisa se engajar na luta contra as desigualdades e se configurar como um veículo social de desconstrução da ordem histórica de perpetuação das injustiças.

Em face de tantos desafios, trazer o cinema para enriquecer as práticas pedagógicas significa abrir caminhos metodológicos criativos para ampliar o olhar dos que o assistem e dos que participam dos debates. O cinema ajudaria a compreender o mundo, as complexas relações humanas e as diferenças que regem a orquestra da vida, tudo de modo participativo. No trabalho aqui desenvolvido, partimos do pressuposto de que o cineclubismo tem por objetivo, segundo Sales (2015), a divulgação, a pesquisa e o debate, constituindo-se, por si só, em um espaço público por excelência, para a construção de um espectador crítico frente à imagem fílmica e a seus desdobramentos sociais e políticos.

O cinema pode fazer-se presente nas escolas de muitas formas, devendo ser explorando não só para facilitar a aprendizagem de determinados conteúdos, ou como forma de lazer, mas de modo a ajudar a ampliar a "experiência fílmica de alunos e professores (MENEZES, 2017 p. 15)". Afinal, o que um filme exibe ultrapassa os conteúdos estudados no currículo escolar, o cinema nos ajuda a refletir sobre o mundo a nossa volta, expondo e questionando a realidade.

A proposta de organizar um cineclube na escola proporciona para professores e para alunos o prazer e a reflexão acerca do tema que o filme aborda. O cineclubismo favorece o diálogo, o debate e a construção de criticidade, destacando a exibição como ato de cultura, servindo como mecanismo de intercâmbio. Ao propiciar a criação de um espaço de convívio entre os atores escolares, o cineclube também favorece o diálogo entre o acervo audiovisual do aluno, decorrente de sua experiência cotidiana e as produções artísticas e culturais, fruto de

Revista Extensão \& Cidadania, v. 9, n. 15, p. 74-92, jan./jun. 2021. 
diferentes contextos históricos e socioculturais. O cineclube na escola pode ajudar a formar cidadãos emancipados politicamente.

Trazer para a escola filmes para trabalhar aproximações entre gênero e sexualidade pode ajudar a superar formas padronizadas, estereotipadas e hegemônicas de olhar a questão e contribuir para questionamentos não menos desafiadores. Nisso, ganha tônica a teoria queer, como suporte metodológico da educação da cultura visual, de modo a descortinar frentes de aproximação com a sexualidade e questões de gênero que desmontam conceitos fundamentalistas, na medida em que ensejam abordagens transdisciplinares de espaços e lugares (BRAGA; BRISOLLA, 2015).

A teoria queer também se destaca por focalizar a construção da identidade, por mobilizar debates na direção de uma desestabilização do sistema que articula o masculino e o feminino a certos corpos. Essa teoria questiona conceitos relacionados ao gênero e seu condão de acomodar o spectrum de identidades, os quais não se relacionam necessariamente com a genitália ou com os cromossomos (GUIDOTTO, 2005). Nesse sentido, Butler (2003), baseando-se em conceitos de Foucault e Derrida, afirma que a diferença e a divergência aniquilam qualquer tentativa de instaurar uma identidade.

O Projeto de Extensão Escolar "Cine Café com Leite" teve um grande desafio, qual seja, descentralizar a heterossexualidade para trazer novas formas de pensar o modo como a cultura e a educação são representados, com vistas a questionar o modo como a sociedade regula os atores sociais ditos diferentes, sobretudo com relação à sua sexualidade e aos seus desejos. Refletir sobre as práticas que tais sujeitos põem em ação para responder a esses desejos foi a questão a que buscamos atender. Além disso, o projeto buscou proporcionar momentos de aproximação entre alunos, professores e equipe gestora por meio de sessões de filmes que abordassem as questões, possibilitando a construção da cultura do respeito, ensejando à comunidade escolar o convívio com situações que possibilitam a apropriação de novos conceitos e valores, de modo a olhar o mundo de forma não normatizadora.

\section{Percurso metodológico}

No ano de 2015, O Programa de Pós-Graduação em Educação e Ciências e Matemática do IFES ofertou uma formação continuada no Campus Cachoeiro de Itapemirim-ES, do IFES (Instituto Federal do Espírito Santo), no campo dos Direitos Humanos, intitulada Gênero e

Revista Extensão \& Cidadania, v. 9, n. 15, p. 74-92, jan./jun. 2021. 
Diversidade na Escola, financiada pela SECADI (Secretaria de Educação Continuada, Alfabetização, Diversidade e Inclusão), da qual participaram 80 professores da educação básica da rede pública municipal, estadual e federal. Professores do programa, alunos e ex-alunos atuaram na formação cujo objetivo era contribuir para a promoção da inclusão social por meio da preparação de professores e profissionais da educação para o enfrentamento de culturas discriminatórias de gênero, étnico racial e de orientação sexual.

Como culminância da formação, os cursistas foram divididos em grupos, os quais deveriam desenvolver e aplicar, em suas respectivas escolas, um projeto de extensão escolar em que se materializasse um dos temas tratados. Este grupo, em específico, implementou, na escola em que atuava, uma intervenção pedagógica, após aprovação pela equipe gestora, materializada no projeto de extensão escolar intitulado "Cine Café com Leite", a cargo de dois professores-alunos participantes da formação continuada.

Os resultados são apresentados neste artigo que se caracteriza por sua natureza qualitativa, cujos dados decorreram da intervenção pedagógica participativa, a qual foi realizada junto aos alunos da terceira série do Ensino Médio da Escola de Ensino Fundamental e Médio "São Jorge” localizada no município de Brejetuba, Espírito Santo, Brasil. A escola está localizada na zona rural do município e funciona nos turnos matutino e noturno, atendendo a um alunado de $6^{\circ}$ ao $9^{\circ}$ do Ensino Fundamental, Ensino Médio, EJA para Ensino Fundamental e Médio e Curso Técnico em Administração. Seu prédio é amplo, possui 12 salas de aula, sala de vídeo, biblioteca, sala de recursos multimídia, salas-ambiente, secretaria, sala de coordenação, direção, sala pedagógica, banheiros distribuídos no térreo e no primeiro andar, cozinha, cantina, pátio, refeitório e uma quadra poliesportiva. A escola contava à época com um grupo de 25 professores, 2 pedagogas, 2 coordenadores, 5 secretários e 400 alunos matriculados.

Compuseram esta intervenção pedagógica 37 alunos, os quais aceitaram espontaneamente colaborar com a pesquisa, após autorização dos gestores, sendo todos informados dos encargos éticos assumidos pelos professores. Por ser uma escola rural, os participantes eram, na maioria, do gênero masculino (70\%), na maioria, trabalhadores rurais.

O desenvolvimento do projeto de extensão consistiu na realização de cinco sessões de filmes que foram exibidos no contraturno da referida turma, sempre às 13 horas, com a duração de quatro horas de sessão, por dia. Antecederam às apresentações discussões sobre diversidade e sobre a teoria queer, no contexto dos Direitos Humanos.

Revista Extensão \& Cidadania, v. 9, n. 15, p. 74-92, jan./jun. 2021. 
Nas sessões, foram projetados os seguintes filmes, conforme a ordem que se segue: "Filadélfia"; "Milk, a voz da igualdade"; "O sorriso de Mona Lisa"; "La Violette" e "Preciosa - uma história de amor e esperança”. Como instrumento de coleta de dados, utilizamos a técnica da observação participante, com registros em diário de campo. Para a coleta dos dados, organizamos estrategicamente rodas de conversa, conduzidas pelos professores, levando em consideração que este tipo de coleta investigativa busca compreender o sentido que o grupo social oferece ao fenômeno estudado. No caso, o fenômeno em estudo se configurava no binômio gênero e sexualidade.

O aporte teórico para esta técnica constitui-se dos estudos de Warschauer $(2001 ; 2002)$; Freire e Shor (1987); Campos (2000); Louro (2001, 2004) e Miskolci (2012). Para estes autores, no contexto da roda de conversa, o diálogo é um momento singular de partilha, uma vez que pressupõe um exercício dialógico, de escuta e fala, estabelecendo relações de horizontalidade. Os relatos de cada participante são construídos a partir da interação com o outro, seja para complementar, discordar ou concordar com o que foi falado anteriormente.

Os dados foram abordados qualitativamente, à luz dos pressupostos teóricos, por meio da utilização de palavras e não de números para descrever as questões sociais analisadas. Segundo Volpato (2013), este tipo de análise é usado em pesquisas sociais, em que se usam técnicas abertas e dialogadas para coletar dados, sendo possível, também, a análise dos relatos em rodas de conversa, situação em que a amostra se apresenta em tamanho reduzido.

\section{Resultados e discussões}

Proporcionar discussões que contribuam para o crescimento pessoal e científico dos alunos dentro do espaço escolar requer a utilização de metodologias diferenciadas. Nesse contexto, a inclusão do cinema nas metodologias de ensino favorece o trabalho com temas polêmicos atuais de maneira contextualizada.

Uma forma de explorar as relações entre as questões polêmicas e o contexto atual pode ser obtida por meio da utilização de material lúdico, no caso a utilização de filmes a partir da criação de cineclubes escolares. Para Duarte (2009), os "filmes de escola" propiciam debates criativos acerca dos principais problemas enfrentados cotidianamente na atividade educacional. A utilização do cinema na escola pode se valer da linguagem que, na maioria dos filmes, é simples e de fácil compreensão e do enredo, que geralmente é tecido para tornar o filme

Revista Extensão \& Cidadania, v. 9, n. 15, p. 74-92, jan./jun. 2021. 
acessível a pessoas de várias idades. A utilização de filmes no trabalho pedagógico colabora para facilitar o ensino de conteúdos diversos, de difícil assimilação, ou de temas polêmicos, caso da proposta que aqui apresentamos. De uma forma ou de outra, a escolha do filme decorre do objetivo e dos conteúdos que orientam a seleção e a prática pedagógica.

O cinema na escola deve buscar desenvolver nos alunos a empatia e o senso crítico. Para Braga e Brisolla (2015), os filmes são produtos da cultura midiática, razão pela qual possuem uma faceta comercial, relacionada à busca pela audiência, como produtos para serem comercializados. Por outro lado, produtos culturais com temáticas homoafetivas costumam escapar dessa lógica comercial, na medida em que discutem temas polêmicos. Filmes com temas dessa natureza abordam dores, feridas, sofrimentos, cuja discussão procuram conduzir os espectadores à compreensão da luta contra a intolerância e as formas de continuar sobrevivendo, apesar das adversidades.

Reflexões assim demandam uma discussão à luz da teoria queer, que surge, segundo Miskolci (2012), como reação e resistência a um momento biopolítico, na meada da década de 1980, que se instaurava em virtude da AIDS (Síndrome da Imunodeficiência Adquirida). A proposta da teoria, segundo o autor, era superar a ideia de uma nação abjeta ou uma nação em que todos sentiam horror como se fosse poluída ou impura.

Desse contexto, emerge a Pedagogia Queer, decorrente de uma iniciativa de pesquisadores da área da Educação, os quais se apropriaram de conceitos da teoria queer para pensar práticas pedagógicas criativas, capazes de fugir das estratégias pedagógicas normativas. No Brasil, Guacira Lopes Louro (2001; 2004) tem sido dos principais expoentes no estudo das contribuições da teoria queer para a área da educação. Esta pesquisadora também discute as inquietações que orientam o desenvolvimento da Pedagogia Queer, reconhecendo-a como um movimento que aponta para o estranho e o excêntrico, que pode se articular com a Educação, campo eminentemente normativo, dedicado ao ajuste dos atores escolares aos padrões sociais.

Uma outra inquietação que Louro $(2001 ; 2004)$ apresenta é como uma teoria nãopropositiva pode "falar" a um campo que vive de projetos, de programas e planos de ação? Qual o espaço da Pedagogia Queer em um campo geralmente voltado para o disciplinamento e a regra? A grande questão a ser discutida é como superar o desafio proposto pelo binarismo e pensar a sexualidade, os gêneros e os corpos de modo plural e múltiplo, de modo a trazer a teoria queer para o contexto das práticas pedagógicas. Essa proposta alinha-se sobretudo com uma pedagogia fundada na prática da liberdade para a construção da cidadania.

Revista Extensão \& Cidadania, v. 9, n. 15, p. 74-92, jan./jun. 2021. 
A Teoria Queer (LOURO, 2004) também contesta a educação heteronormativa e seus conservadorismos, que não reconhece a relevância de práticas inclusivas nos currículos, não admitindo a diversidade, em prol do binarismo fundante da heterossexualidade compulsória. Setores conservadores ocultam sua ideologia por intermédio da expressão "ideologia de gênero", a qual desqualifica a diversidade.

Ajudam a ampliar um pouco a discussão as reflexões de Butler (2000), para quem as sociedades constroem normas que regulam e materializam o sexo dos atores sociais, as quais se firmam por intermédio da sua repetição, para que a materialização se concretize. Ocorre que corpos em movimento nunca se conformam às normas impostas, isto é, as normas que tornam a forma heterossexual um padrão, uma forma conservadora de se relacionar.

Fiel a esse quadro teórico, o projeto de extensão iniciou-se com a apresentação, na primeira sessão, do filme "Filadélfia", que retrata a vida de um advogado homossexual soropositivo, que trabalha para uma grande firma na cidade de Filadélfia e é vítima de vários tipos de preconceito. Quando fica impossível para ele esconder dos colegas de trabalho o fato de que tem AIDS, é demitido e resolve contratar um advogado homofóbico para levar seu caso até o tribunal.

Pôde-se observar muita comoção por parte dos participantes, durante a exibição do filme, o qual retratava não somente a humilhação vivida pelo trabalhador, mas sua luta pela sobrevivência. O enredo girava em torno dos personagens Andrew Beckett (interpretado por Tom Hanks), portador do vírus da AIDS, que contrata os serviços de seu colega de profissão, Joe Miller (Denzel Washington). A produção artística explora a batalha entre o preconceito de Joe e seu desejo de justiça em favor de Andrew. Foram analisadas as seguintes cenas: o julgamento; a conversa de Joe com sua esposa sobre o caso; Andrew discutindo com seu parceiro Miguel sobre pular o tratamento uma noite; o apoio da família de Andrew, na luta contra a doença e Andrew recitando a tradução de uma ópera para Joe, durante um ensaio para o interrogatório.

Esta cena foi considerada, pelos alunos, com um dos momentos mais emocionantes do filme. Como ponto de crítica, os alunos apontaram a lentidão e a burocracia da justiça, o que é indicativo da forma preconceituosa como as instituições sociais conduzem a questão. Somente após sua morte, o personagem Andrew venceu o caso, recebendo uma indenização volumosa. Mas, qual a finalidade da indenização se a vida já havia escoado? O cineclube colaborou não apenas favorecendo um momento de apropriação do filme pelo grupo, mas também como um

Revista Extensão \& Cidadania, v. 9, n. 15, p. 74-92, jan./jun. 2021. 
momento de ressignificação simbólica. Isto é, ajudou na formação de consciência crítica, ampliando as potencialidades questionadoras dos alunos (LOURO, 2004).

Ao discutir o drama cotidiano da personagem principal do filme e sua forma sofrida, mas corajosa de viver, os alunos apontaram o desafio que é para os portadores da AIDS sobreviverem na sociedade atual. Até que ponto o preconceito com a doença ultrapassa as relações humanas e exclui o portador do convívio social? Ao discutir acerca das lutas das pessoas infectadas, os alunos puderam pensar sobre a natureza invasiva dos tratamentos de choque utilizados no final dos anos 80 e no início dos anos 90.

$\mathrm{O}$ advento da epidemia da AIDS excluiu a sexualidade homoafetiva, tornando-a, pela simples razão de ser, uma doença. O homem gay era metáfora da AIDS, essa representação social fortaleceu a naturalização da heterossexualidade, da heteronormatividade. A heterossexualização da sociedade fortaleceu discursos fundamentalistas e proliferou a intolerância. Nos anos finais da década de 80, as pessoas chamavam os gays de "AIDS", relegando-os a sinônimo de doença. Para Miskolci (2012), quando se xinga alguém de algo, não se está apenas dando um nome para essa pessoa, o que fazem é julgar a pessoa, classificando-a como objeto de nojo, isso porque a injúria classifica alguém de quem a sociedade quer distância.

É possível trazer a intolerância tratada no filme para o caso da realidade brasileira, em que, nas grandes cidades, constrói-se uma espacialidade gay, que decorre da compartimentação da cidade feita pela sociedade. A espacialidade gay resume-se a locais que a sociedade lhe permite escolher. Essa espacialidade gay pode ser conhecida como guetos gays, onde se concentram bares, boates e espaços de encontros, que fervilham contatos e diálogos. A chegada da AIDS e de seu estigma destruíram a vida noturna gay do Rio, de Belo Horizonte e de São Paulo. Ao se destruírem os espaços urbanos de encontro, destruía-se o desejo, estrangulava-se a vida e destruía-se a autoestima. Nesse momento, a homofobia revelava seu lado mais cruel, pois a AIDS passou a ser chamada de "câncer gay", contexto em que se acentuou a exclusão, o desprezo e a intolerância (LOURO, 2001).

O debate sobre essas questões foi motivado pela exposição fílmica. Para Menezes (2017), como qualquer obra de arte, o cinema comunica uma mensagem capaz de provocar o espectador, o que, de fato, ocorreu em virtude da forma como o tema foi desenvolvido. Colaboraram para essa finalidade os vários aspectos do filme, entre os quais o ângulo das

Revista Extensão \& Cidadania, v. 9, n. 15, p. 74-92, jan./jun. 2021. 
imagens, o enquadramento das cenas, a interpretação do elenco, a montagem de planos, tudo ajudou na compreensão da mensagem.

Baseado na história real de Harvey Milk, o filme "Milk, a voz da igualdade", é uma obra didática e documental sobre o primeiro político abertamente homossexual da história dos Estados Unidos, eleito em 1977 para o quadro de supervisor da cidade de São Francisco. Aos 47 anos, Harvey Milk marcou a história como o primeiro gay ativista que conseguiu exercer um cargo no serviço público americano. Infelizmente, foi assassinado, um ano depois, e os motivos para o crime são sugeridos como sendo razões banais e enigmáticas. Mais que instrutivo, o filme trata da ambição, da coragem e do heroísmo que transformaram o personagem Milk em mártir, que lutou com paixão pela equidade de direitos para os homossexuais, com o objetivo de mudar vidas.

Na roda de conversa, foram destacados momentos do filme, tais como os episódios em que o político, ao iniciar um discurso, se dirigia à multidão dizendo: "Meu nome é Harvey Milk e eu quero recrutá-lo!" e "Todos os homens foram criados iguais", ou "Sem esperança não vale a pena viver". Estes aspectos (MENEZES, 2017) mostraram-se marcantes para os alunos participantes e culminaram em um rico momento de relatos reveladores de que a mensagem que o filme pretendia socializar alcançou a todos. Os alunos destacaram a relevância do respeito às diferenças; alguns enfatizaram a importância de lutar pelos nossos sonhos e objetivos. Houve muitas discussões sobre os sentidos de responsabilidade e de humanidade contidos no filme. O foco das discussões recaiu sobre a política de segregação e de intolerância, já a opressão, o terror e o preconceito revelaram-se no filme de modo subliminar. A sexualidade não foi explorada abertamente, mas a presença velada do poder da hegemonia heterossexual camuflando formas de injustiças sociais e políticas permitiu observar que a sexualidade foi eclipsada nas cenas de opressão.

Os alunos se manifestaram acerca da forma ideológica como o filme foi organizado, mostrando a supremacia das relações padronizadas, as quais impedem os modos de vida que não se coadunam a este padrão. Reflexões assim revelam-se como formas pedagógicas de desenvolver um processo educativo que traz novos sentidos para o estranho, funcionando como veículo de mudança cultural (MISKOLCI, 2012). Ao discutirmos modos de desconstruir o binário, temos a oportunidade de questionar formas já segmentadas:

A desconstrução das posições binárias tornaria manifesta a interdependência e a fragmentação de cada um dos polos. Trabalhando para mostrar que cada

Revista Extensão \& Cidadania, v. 9, n. 15, p. 74-92, jan./jun. 2021. 
polo contém o outro, de forma desviada ou negada, a desconstrução indica que cada polo carrega vestígios do outro e depende desse outro para adquirir sentido. (LOURO, 2001, p. 548)

Na terceira sessão foi apresentado o filme "O Sorriso de Monalisa", o qual destaca o papel da mulher na sociedade e como se criou a representação de que cabia à mulher os cuidados com o lar e com a prole, devendo esta abrir mão da sua profissionalização. O filme foi baseado em um contexto histórico de padrões diferentes. Nos diálogos realizados após a projeção, buscamos trazer o questionamento acerca do papel social da mulher, suas contribuições para a socialização da igualdade de gêneros e reconhecer a importância do contexto histórico de emancipação feminina, evitando julgamento atemporal.

Os debates acerca desse filme evidenciaram momentos calorosos, a partir do tema "machismo". Ao debaterem sobre a frase de Simone de Beauvoir "Ninguém nasce mulher; torna-se mulher", os alunos, em sua maioria, concordaram que são as instâncias socializadoras que transformam o ser humano em feminino ou masculino e começaram a compreender as questões de gênero e a compreender que a naturalização das instituições também se configura em um problema. Quem criou as regras? Em quem se pensou? Por que as regras foram criadas? Por que a "maternagem" precisa ser feminina? Quais regras culturais fundamentam isso? Ao desenvolvermos a postura crítica, conseguimos empreender debates acerca de alguns aspectos relativos à questão da aprendizagem, mostrando que, por meio da arte, os alunos podem construir um olhar mais sensível sobre o mundo.

Houve avanços na forma de entender como certos temas polêmicos se naturalizaram e se tornaram hegemônicos. Foi nesse movimento que a sensibilização do olhar sobre a vida se aflorou, destacando cenas em que as disputas e conflitos entre gêneros, revelados a partir da competição no mercado de trabalho, ganharam tônica no filme. Serve de exemplo a cena em que a professora promove uma educação que pretende mudar o modo a partir do qual as alunas se percebem, conduzindo-as a uma percepção que ultrapassa à de dona do lar, compreendendoas como seres humanos completos, dotados de potencialidades.

Discutindo o projeto feminista e a complexidade que envolve o processo de representação, Butler (2003) questiona a centralidade e a categoria estável de mulher. Considerada dessa forma, a representatividade serve como:

[...] termo operacional no seio de um processo político que busca estender visibilidade e legitimidade às mulheres como sujeitos políticos; por outro lado,

Revista Extensão \& Cidadania, v. 9, n. 15, p. 74-92, jan./jun. 2021. 
a representação é a função normativa de uma linguagem que revelaria ou distorceria o que é tido como verdadeiro sobre a categoria das mulheres. (BUTLER, 2003, p. 18)

A representação política não é, portanto, uma forma positiva de descrever grupos de indivíduos. A representação é processo de constituição da diferença, lembrando que, para Butler (2003), gênero não é algo que se é, mas algo que se faz nas ações que acontecem. Isso significa que cada sujeito faz seu gênero.

Já o filme "Violette" retrata a vida de Violette Leduc, que encontra Simone de Beauvoir em Paris, nos anos que precedem a Segunda Guerra Mundial. Começa, então, uma relação intensa entre as duas mulheres que dura toda a sua vida. Trata-se de uma relação baseada na busca pela liberdade e pela escrita - por parte de Violette - e na convicção de que Simone tinha nas mãos o destino de uma escritora fora do normal. $\mathrm{O}$ filme retrata a questão do estereótipo, materializado na personagem principal, representada por uma atriz que não segue o padrão de beleza determinado pela sociedade. Outro ponto importante do filme são as relações no mercado de trabalho e familiar, pois a personagem Violette vivia de trocas de alimentos no mercado negro francês durante a Segunda Guerra Mundial. Fora isso, vivia uma relação conturbada com os pais e mostrava-se demasiadamente carente, o que dificultava que alguém, homem ou mulher, mantivesse com ela uma relação amorosa.

A construção ideológica do filme denota o sentido autoritário da narrativa, situando, no mesmo patamar, o sentimento, o afeto e as necessidades fisiológicas do corpo. Ao tornar o corpo um campo minado, incapaz de sediar um mínimo momento de romantismo, o filme explora as limitações das escolhas pessoais da personagem de modo a superar o momento histórico em que vivia.

Na roda de discussão, os alunos destacaram que os sofrimentos e os entraves vividos pela personagem, se fossem explorados de modo apropriado, poderiam se transformar em um grande alicerce para o sucesso. Uma aluna lembrou que para que uma ferida se abra, é necessário que algo corte a pele. Ao buscar a cura para suas feridas, a personagem demonstrou seu poder de superação.

Na última sessão, houve a apresentação do filme "Preciosa - uma história de esperança". O enredo mostra a história de Claireece Preciosa Jones, uma adolescente de 16 anos, residente no Harlem, Nova York. Preciosa cresceu e viveu em um ambiente hostil, em que se defrontou com muitas adversidades, tais como a pobreza e o preconceito, pois, além de negra, era também obesa e foi mãe adolescente. A personagem foi, também, vítima de múltiplas formas de

Revista Extensão \& Cidadania, v. 9, n. 15, p. 74-92, jan./jun. 2021. 
violência em seu próprio lar, tais como, a negligência dos pais com relação a sua saúde e educação, episódios constantes de violência psicológica causados por sua mãe e momentos de violência física e sexual perpetradas pela sua mãe e seu pai. Os dois filhos de Preciosa decorreram do abuso sexual sofrido.

Além das agressões domésticas, Preciosa era vítima de bullying pelos colegas da escola. Como reflexo, Preciosa, personagem principal, não conseguia se relacionar com os pares e costumava se manter sentada, em silêncio, na última carteira da sala de aula durante todo o período letivo, não saía da sala nem para utilizar o banheiro. Dessa forma, chegou aos 14 anos de idade, sem compreender o que os professores lhe ensinavam, abandonada no fundo da sala de aula por todos. Ao engravidar pela segunda vez, foi expulsa da escola regular e convidada a frequentar uma escola alternativa. Neste momento, conheceu uma professora que lhe ofereceu uma educação mais inclusiva, devotando-lhe um relacionamento mais respeitoso. Com isso, novas amizades foram estabelecidas, a vida lhe proporcionou uma nova chance de ser feliz e de superar os desafios.

$\mathrm{Na}$ roda de conversa, os debates foram intensos, houve muita discussão sobre as representações de corpo (raça, obesidade e beleza), sobre violência sexual e sobre os aspectos relacionados à vulnerabilidade, à educação inclusiva e às formas de emancipação social. Para Menezes (2017), a experiência fílmica busca discutir vivências por meio da análise, de modo a ensejar uma provocação sobre o conteúdo para a formação de subjetividades críticas.

Todos os pesadelos abordados no filme, de alguma forma, foram vivenciados por muitos atores escolares brasileiros, em suas múltiplas e distintas realidades. Os alunos participantes do debate destacaram, sobretudo as meninas, as cenas em que Preciosa usava a imaginação para se projetar em uma figura famosa, cercada por fãs e bem cuidada, o que aponta a importância da esperança na vida de todos. Embora não fosse essa a realidade da jovem, mas a de uma cruel luta para sobreviver com um filho deficiente e outro portador do vírus HIV, a esperança a mantinha viva.

Mesmo que as pessoas possam mostrar-se fortalecidas em virtude das adversidades pelas quais passaram, algumas marcas da violência jamais se cicatrizam, algumas feridas jamais se curam, havendo necessidade de constante acompanhamento psicológico e social. Este filme trata de uma história de superação dos obstáculos diários que muitos precisam enfrentar para sobreviver.

Revista Extensão \& Cidadania, v. 9, n. 15, p. 74-92, jan./jun. 2021. 
O Projeto Cine "Café com Leite" teve a duração de cinco dias, em cujo transcurso foram desenvolvidos debates calorosos. É importante destacar a relevância das atividades de extensão escolar, as quais podem funcionar como um meio transformador que proporciona um olhar crítico e uma posição ativa em face do campo que se analisa. Segundo Salles (2015), as imagens cinematográficas exibidas podem levar os alunos à inquietação e, com isso, criar bases para mudanças culturais e subjetivas, permitindo que os alunos entrem em contato com muitas realidades, ultrapassando a lógica capitalista da individualidade. Ao se constituírem a partir de sua criticidade, os alunos podem se tornar cidadãos críticos e políticos.

Com relação às imagens de todos os filmes, é possível apontar que elas repercutiram nos alunos oportunidades de lhes estimular a livre expressão. Neste sentido, eles entenderam que a convivência com o diferente é um desafio, porque foge dos padrões sociais impostos. A liberdade também foi mencionada na roda de debates, porque a ausência de controle e de censura nos temas discutidos permitiu que os alunos se manifestassem acerca de questões polêmicas.

Uma das alunas mencionou que todos devem ter sua individualidade respeitada, a subjetividade é um direito do cidadão. "Todos devemos ter respeito e acolhimento por ser diferente", foi o depoimento dessa aluna. Os alunos mencionaram o fato de que todos podiam se manifestar nesse projeto e não houve uma orientação, por parte dos professores, do que eles deveriam dizer, fato que lhes trouxe grande motivação. Em razão de não ter sido imposto aos participantes do projeto um padrão de comportamento, eles se sentiram com liberdade de manifestar sua opinião. Um aluno revelou que a proposta da pedagogia queer não é normatizar ninguém, mas defender atitudes de respeito e de acolhimento para com todos.

Ao tratarmos, na roda de debates, sobre os desafios do projeto com os alunos, foi possível observar, por unanimidade, que desconstruir os preconceitos enraizados a respeito da diversidade é uma questão que pode ser discutida. Muitos alunos se manifestaram favoráveis a atitudes mais tolerantes e mais respeitosas. Mostrar que o diferente é visto como imprevisível e traz consigo o preconceito e a discriminação foi um dos propósitos deste projeto, o qual conseguiu repercutir nos alunos como esta visão equivocada é geradora de sofrimento e de exclusão social.

Muitos foram os relatos dos alunos acerca do preconceito, do sofrimento e do bullying. A partir dos diversos depoimentos, foi possível constatar que a convivência pode contribuir para a superação de visões preconceituosas a respeito da diversidade. Uma aluna relatou que

Revista Extensão \& Cidadania, v. 9, n. 15, p. 74-92, jan./jun. 2021. 
"sem saber, eu percebo agora que sou preconceituosa, mas quero mudar". Os professores intervieram respondendo que este é um trabalho contínuo e processual. Ocorre que ninguém deixa de ser preconceituoso de uma hora para outra, mas este é o caminho, pois se desvencilhar de conceitos que estão há tempos enraizados em nós e na própria sociedade demanda esforço (LOURO, 2004).

Discutir todas as histórias denunciadas nos filmes levou os alunos participantes do projeto a perceberem a natureza agressiva e insidiosa da opressão, a natureza cruel da intolerância e as formas excludentes que decorrem dos modos culturais de naturalizar o poder masculino e as formas como um Estado patriarcal destrói as diferenças em favor de um modelo de sociedade. Nesse cenário, houve a discussão sobre as cenas que provocavam questionamentos sobre a busca de afirmação de identidades, movimento por meio do qual se almeja a demarcação de contornos e a negação dos opostos. Como conclusão, os professores lançaram uma reflexão aos alunos, qual seja, como pensar a sexualidade e os corpos de forma plural? Eis o desafio de uma pedagogia queer, a qual se volta para o processo de produção das diferenças e trabalha com a instabilidade de todas as identidades. Nisso, a diferença deixaria de estar do lado de fora e integraria o eu, questionando as relações entre o eu e o outro (LOURO, 2001) e a polarização heterossexualidade/homossexualidade seria questionada.

\section{Considerações finais}

Ao provocar o exercício regular de levar os alunos a participar de projetos de caráter cineclubista, a escola os aproxima da experiência crítica. Em uma sala de cinema, no Shopping, por exemplo, não é possível o debate, no transcurso da exibição, já, no cineclube, é possível ao professor fazer pausas na exibição para provocar um debate, o que torna o momento rico para trocas de experiências. Dessa forma, o projeto contribuiu para a formação crítica dos alunos, na medida em que os estimulou a buscar, de modo mais consciencioso, posicionamentos diante das obras cinematográficas. Na organização da sessão cineclubista, os alunos foram incentivados a assumir o protagonismo, tornando-se responsáveis pelos desdobramentos após a sessão.

É possível destacar que houve um avanço nas formas de se posicionar diante dos temas e na qualidade das observações apresentas pelos alunos na roda de debates. Isso foi observado junto a maior parte do grupo, em especial, aos que participaram com mais efetividade das

Revista Extensão \& Cidadania, v. 9, n. 15, p. 74-92, jan./jun. 2021. 
sessões. Verificamos a relevância de estratégias como as desenvolvidas que contaram com a participação ativa dos jovens, as quais lhes permitiram compartilhar suas experiências.

Os debates gerados na roda de conversa revelaram conflitos de valor socialmente construídos, aprendidos e tidos como verdadeiros e absolutos. Em toda obra de arte, bem como no cinema, o filme comunica algo e leva o leitor a um posicionamento. Essa provocação foi possível de ser observada. Os gestos de negação e reprovação observados nos alunos, ao assistirem a algumas cenas, evidenciaram avaliação de condutas. Várias cenas apresentadas nos filmes fizeram com que alguns alunos percebessem que já haviam sido vítimas daquele preconceito. Citamos, como exemplo, a personagem obesa do filme Preciosa, a personagem Milk e a personagem Violette, duas alunas, ao final, disseram terem sido vítimas de preconceito, esse depoimento aproxima a ficção da realidade, a arte da realidade.

Um resultado louvável foi que o cineclube conseguiu melhorar a sociabilidade e a timidez de alguns alunos. Resultados, assim, validam a importância da experiência com o cineclube para fomentar o debate em torno de temas polêmicos para ajudar os alunos tímidos a se posicionarem diante dos temas e para suscitar questionamentos, estranhamentos e debates.

$\mathrm{O}$ projeto conseguiu mostrar como existem resistências à mudança de práticas e à superação de preconceitos. Ao convidarmos outros professores para participar da roda de debates final, muitos não se dispuseram a participar do projeto. Muitos deles - conforme relato dos alunos - evitavam tocar no assunto, quando ele era ventilado em suas aulas. Alguns alunos se sentiram constrangidos ao debater os temas fora das sessões do cineclube. Uma pedagogia associada à teoria queer é assim, subversiva e provocadora, pois ela mostra o queer naquilo que é tomado como normal.

Debates públicos geram argumentações calorosas sobre o preconceito e a intolerância no Brasil e sempre trazem à baila relatos como “eu não tenho preconceito". Será mesmo? Ou será que a visão de quem diz isso é a padronizada? Alguém já conseguiu colocar-se no lugar daquele que é vítima de bullying: o aluno gordinho, o aluno gay, a menina feminista? Todos sofrem por serem diferentes, todos possuem feridas provocadas pelo falso mundo globalizado e cibernético. O desafio não é tolerar, mas conviver e respeitar as diferenças, vez que a única coisa de igual que o ser humano possui é sua diferença e nisso reside a razão de ser da diversidade cultural.

Começamos este artigo com o objetivo de socializar os resultados de um projeto de extensão desenvolvido em escola localizada nas montanhas do estado do Espírito Santo. A localização da escola é distante dos grandes centros da região Sudeste, mas as dores que foram

Revista Extensão \& Cidadania, v. 9, n. 15, p. 74-92, jan./jun. 2021. 
identificadas em seus atores escolares, vítimas de preconceito e de intolerância, são idênticas às feridas que alguns personagens dos filmes possuem por serem diferentes e por não se conformarem aos padrões moralistas. Começamos o artigo buscando proporcionar uma reflexão crítica sobre nós, sobre os outros, sobre a experiência com o outro, sobre a experiência de ser diferente. Acreditamos que conseguimos, pelo menos, uma coisa: que os alunos percebessem que as nossas dores são iguais às dores deles. Que as nossas feridas são semelhantes às deles. Talvez isso nos ligue a eles. Se vamos mudar nosso jeito de olhar o queer que vive no mundo, o tempo dirá, mas podemos fazer com que nossas feridas se transformem não em cicatrizes, mas em pontos de partida para a cura, não só de nossas dores, mas das de nossos semelhantes.

\section{Agradecimentos}

Agradecemos à SECADI pelo financiamento do projeto de formação continuada e à Diretoria de Pesquisa e Extensão do IFES Campus Cachoeiro de Itapemirim, ES, e aos gestores da Escola Estadual São Jorge pelo apoio ao projeto de extensão.

\section{Referências}

BRAGA, Monica M. M.; BRISOLLA, Marcia R. S. Gênero e sexualidade no cinema: uma discussão a partir da educação da cultura visual. VIII Seminário Nacional de Pesquisa em Arte e Cultura Visual: arquivos, memórias, afetos, 8, 2015, Goiânia. Anais... Goiânia, GO: UFG/ Núcleo Editorial FAV, 2015.

BUTLER, Judith. Problemas de gênero: feminismo e subversão da identidade. Rio de Janeiro: Civilização Brasileira, 2003.

CAMPOS, Gastão Wagner Souza. Um método para análise e cogestão de coletivos: a constituição do sujeito, a produção de valor de uso e a democracia em instituições: o método da roda. São Paulo: Hucitec, 2000.

CAVALCANTI, Marcus Alexandre Pádua; FERREIRA, Sandramor do Amaral. Pedagogia Queer: uma nova proposta no meio educacional. Revista de Pesquisa Interdisciplinar, Cajazeiras, n. 2, suplementar, p. 12-21, set. 2017.

DUARTE, Rosália. Cinema \& Educação. 2. ed. Belo Horizonte: Autêntica, 2009.

FREIRE, Paulo; SHOR, Ira. Medo e ousadia. Rio de Janeiro: Paz e Terra, 1987.

Revista Extensão \& Cidadania, v. 9, n. 15, p. 74-92, jan./jun. 2021. 
PESSANHA, Jackelline F. A Educação inclusiva e as relações homoafetivas. 2012.

Disponível em: http://www.publicadireito.com.br/artigos/?cod=0172d289da48c48d. Acesso em: 14 jan. 2020.

GUIDOTTO, Nadia. Sharingscars, healingourselves: Theory in praxis. Canadian Online Journal for Queer Studies in Education, v. 1, n. 3, p. 1-17, 2005.

LOURO, Guacira. Teoria Queer - uma política pós-identitária para a educação. Estudos Feministas, v. 2, p. 541-553, 2001.

LOURO, Guacira Lopes. Um corpo estranho - ensaios sobre sexualidade e teoria queer. Belo Horizonte: Autêntica, 2004.

MENEZES, Luciana B. A arte do encontro: o Cineclube na escola. Revista Entreideias, Salvador, v. 6, n. 1, p. 11-26, jan./jun. 2017.

MISKOLCI, Richard. Teoria Queer: um aprendizado pelas diferenças. Belo Horizonte: Autêntica, 2012.

SALES, Priscila Constantino. O movimento cineclubista brasileiro e suas modulações na recepção cinematográfica. XXVII Simpósio Nacional de História: lugares dos historiadores velhos e novos desafios, 28, 2015, Florianópolis. Anais... Florianópolis: Universidade Federal de Santa Catarina, 2015.

VOLPATO, Gilson L. Ciência, da filosofia à publicação. 6. ed. São Paulo: Cultura Acadêmica, 2013.

WARSCHAUER, Cecília. Rodas em rede: oportunidades formativas na escola e fora dela. Rio de Janeiro: Paz e Terra, 2001.

WARSCHAUER, Cecília. A roda e o registro: uma parceria entre professor, aluno e conhecimento. Rio de Janeiro: Paz e Terra, 2002.

Recebido: 06.05.2021

Aceito: 19.06 .2021

Revista Extensão \& Cidadania, v. 9, n. 15, p. 74-92, jan./jun. 2021.

ISSN 2319-0566 DOI: 10.22481/recuesb.v9i15.8721 